Volume 7, Issue 1 (2020)

\title{
Effect of Sodium Chloride on Corrosion Inhibition Efficiency of Polyethylene Coatings on Alloy Steel at Ambient Temperature
}

\author{
Anyanwu K. O. ${ }^{1}$, Ogu I. S. ${ }^{1}$, Nzei H. O. ${ }^{2}$ \\ ${ }^{1}$ Department of Materials and Metallurgical, Federal University of Technology, Owerri, Nigeria; \\ ${ }^{2}$ Department of Civil Engineering, Federal University of Technology, Owerri, Nigeria
}

\section{Article info:}

Paper received:

The final version of the paper received:

Paper accepted online:
*Corresponding email:

January 31,2020

June 5, 2020

June 19, 2020

\author{
kings.onyekaa2016@gmail.com
}

\begin{abstract}
An investigation was conducted on the effect of sodium chloride concentration on corrosion inhibition efficiency of High-Density Polyethylene (HDP) coating on alloy steel in sodium chloride solutions of different degrees of salinity. In the study, four test media were used: the first is 201 of distilled water in a rectangular base plastic container; the second is 201 of distilled water in a rectangular base plastic container in which $200 \mathrm{~g}$ of sodium chloride $(\mathrm{NaCl})$ was dissolved entirely, giving a concentration of $10 \mathrm{~g} / 1\left(0.01 \mathrm{~g} / \mathrm{cm}^{2}\right)$. Similarly, the third medium is 20 litres of distilled water in which $300 \mathrm{~g}$ of $\mathrm{NaCl}$ was dissolved entirely, having $15 \mathrm{~g} / 1\left(0.015 \mathrm{~g} / \mathrm{cm}^{2}\right)$ concentration. The fourth medium is prepared by dissolving $400 \mathrm{~g}$ of $\mathrm{NaCl}$ in 20 litres of distilled water, resulting in $20 \mathrm{~g} / \mathrm{l}$ $\left(0.02 \mathrm{~g} / \mathrm{cm}^{2}\right)$ concentration. The container used for each medium is a rectangular base plastic container. Twenty-eight (28) uncoated and twenty-eight (28) polyethylene-coated alloy steel coupons of dimension $5 \times 30 \times 50 \mathrm{~mm}$ with an $8 \mathrm{~mm}$ diameter hole each were used for this investigation. Seven coated coupons each were wholly immersed in 10 , 15 , and $20 \mathrm{~g} / \mathrm{l}$, and zero salinity distilled water. Similarly, seven uncoated coupons each were immersed entirely in 10,15 , and $20 \mathrm{~g} / \mathrm{l}$ and zero salinity distilled water. The coupons in various test media were exposed to ambient temperature for a total of 49 days. One coupon from each of the media is reweighed on weekly bases and the weight loss $(\mathrm{g})$, corrosion rate ( $\mathrm{mm} /$ year), and corrosion inhibition efficiency were calculated and recorded. From the results obtained, the corrosion rate of the coupons increases with an increase in sodium chloride solution. It is also observed from the results obtained considering the variation of corrosion rates of polyethylene coated coupons with sodium chloride concentration and the variation of corrosion rates of uncoated coupons with sodium chloride concentration that the corrosion rate of the coupons is lesser with the polyethylene coating compared with the uncoated coupons. The results show that the corrosion rate of coupons falls over time, and more rapidly at an early time of exposure, say the first week. From the result of the variation of corrosion inhibition efficiencies of polyethylene coated coupons with sodium chloride concentration, it is observed that the corrosion inhibition efficiency of polyethylene decreases over time and decrease also with an increase in sodium chloride concentration.
\end{abstract}

Keywords: alloy steel, coating, corrosion inhibition, high-density polyethylene, sodium chloride.

\section{Introduction}

Alloy steel has good mechanical properties, such as yield strength, hardness, and toughness. They are widely used in engineering works. Alloy steel has up to $500 \mathrm{MPa}$ yield strength, a density of about $7800-7860 \mathrm{~kg} / \mathrm{m}^{3}$. They have good creep resistance and a high melting point of about $1350-1400^{\circ} \mathrm{C}$. They are used in structural works, pipelines, concrete reinforcement, etc. Conversely, alloy steel has low corrosion resistance. Its corrosive nature deteriorates its mechanical properties when they are exposed to aggressive media, leading to poor performance within service life, poor durability, or catastrophic failure.

Corrosion is the product of the interaction between metallic materials and the environment in which they are exposed, depending on the type of environment and the number of prevailing conditions [1]. Corrosion is also defined as the depreciation of metals due to the redox reaction between the metal to different substances in their environment then later produce undesirable compound [2]. Corrosion occurs if the half-cell reaction which releases electrons is in connection with the half-cell reactions which receive electrons. 
For iron, the corrosion process is given as $\mathrm{Fe}(\mathrm{s})+\mathrm{H}_{2} \mathrm{O}(\mathrm{c})+1 / 2 \mathrm{O}_{2}(\mathrm{~g})=\mathrm{Fe}(\mathrm{OH})_{2}(\mathrm{~s})$. The Ferro Hydroxide $\left[\mathrm{Fe}(\mathrm{OH})_{2}\right]$ is a temporary result which later oxidizes naturally by water and air into Ferri Hydroxide $\left[\mathrm{Fe}(\mathrm{OH})_{3}\right], \quad$ i. e. $\quad 4 \mathrm{Fe}(\mathrm{OH})_{2}(\mathrm{~s})+\mathrm{O}_{2}(\mathrm{~g})+2 \mathrm{H}_{2} \mathrm{O}(\mathrm{l})=$ $=4 \mathrm{Fe}(\mathrm{OH})_{3}(\mathrm{~s})$.

The Ferri Hydroxide then dehydrates to form Fe2O3, which is reddish-brown deposit, usually referred to as rust, i. e. $2 \mathrm{Fe}(\mathrm{OH})_{3}=\mathrm{Fe}_{2} \mathrm{O}_{3}+3 \mathrm{H}_{2} \mathrm{O}$ [3].

\section{Literature Review}

Commendable efforts have been made by several researchers, and reasonable results have been achieved on the measures for mitigating corrosion of steel. Mitigation of corrosion of steel starts from the liquid state of the steel at which corrosion-resistant elements are used to alloy the steel, such as chromium, which lowers the diffusion rate of carbon from the matrix to the grain boundaries of the steel. This minimizes the chances of intergranular corrosion of the steel. This is achieved by the chromium tieing itself with the carbon in the matrix, forming chromium carbide $\left(\mathrm{Cr}_{3} \mathrm{C}_{2}\right)$ against carbon migrating to the grain boundary to form cementite or iron carbide $\left(\mathrm{Fe}_{3} \mathrm{C}\right)$ which is a hard phase and corrosion site. Inorganic coatings and organic inhibitors have been developed to fight the corrosion of metals. Material selection in design and electrical methods are also effective methods widely adopted in fighting corrosion of metals.

Inorganic inhibitors have active groups; they are amino, which decreases the corrosion rate of metals [4]. They include Sodium Nitrite, Chromate, Phosphate, Zinc, etc. Sodium nitrite is not always recommended because it is required at high concentrations compared to others, usually $(300-500 \mathrm{mg} / \mathrm{l})$, so it is not economical. Chromate and zinc are toxic, and phosphate is considered as a pollutant [5]. Other than the inorganic inhibitors, organic inhibitors are in use. They are grouped into synthetic and organic from nature extractions [6]. Compounds used as organic inhibitors usually consist of nitrogen, sulfur, or oxygen atoms having a pair of free electrons [7].

Metals are also protected against corrosion using polymeric coatings, ceramic coatings, and concrete coatings. Polymeric coating in use includes an epoxy resin, high density, and low-density polyethylene, polyurethane, bituminous coatings (slow curing (SC), medium curing (MC) and Rapid curing (RC), etc. This research is thus aimed at determining the effect of concentration of sodium chloride on the corrosion inhibition efficiency of polyethylene on alloy steel in sodium chloride solutions of different levels of salinity at ambient temperature.

\section{Research Methodology}

\subsection{Corrosion and control measure}

The most common form of corrosion is rusting. It is the oxidation of iron from iron (II) ion to iron (III) ion in the presence of water and oxygen, which gives a reddishbrown deposit called rust. It is described by the chemical reaction equations given below:

$$
\mathrm{Fe}(\mathrm{s})+6 \mathrm{H}_{2} \mathrm{O}(\mathrm{c})+3 \mathrm{O}_{2}(\mathrm{~g})=4 \mathrm{Fe}(\mathrm{OH})_{3}(\mathrm{~s}) .
$$

Generally, corrosion rate is given by [7]:

$$
C R=\frac{\Delta W}{D^{*} A^{*} T},
$$

where $C R$ - corrosion rate; $\Delta W$ - weight loss; $D-$ density; $A$ - surface area of metal exposed to corrosion environment; $T$ - exposure time.

Corrosion inhibition efficiency is a parameter that shows the effectiveness and durability of corrosion control measures over a given period. It is generally expressed as follows:

$$
\% I E=\frac{C R^{o}-C R}{C R^{o}} \times 100,
$$

where $\% I E-$ percentage corrosion inhibition efficiency; $C R^{0}-$ corrosion rate without inhibitor in the medium.

According to Aisha H. Al-Moubaraki [8], the percentage of corrosion inhibition efficiency is given by [8]:

$$
\% I E_{W L}=\left(1-\frac{e_{W L}}{e_{W L}^{o}}\right) \times 100,
$$

where $\% \mathrm{IE}_{\mathrm{WL}}$ - percentage inhibition efficiency in terms of weight loss; $e_{W L}-$ Corrosion rate with inhibitor; $e^{0}{ }_{W L}$ - corrosion rate without inhibitor.

\subsection{Experiment}

Three pieces of samples, tagged $X 2, X 2$, and $X 3$, were randomly cut off from a length of structural steel bar and were analyzed in the laboratory using a spectrometer and universal tensile test machine. The geometry of the coupons used is shown in Fig. 1. As shown in Table 1, the spectrometer and Universal Testing Machine (UTM) test results of the samples indicate that the material is alloy steel. From the steel bar, twenty-eight (28) uncoated and twenty-eight (28) polyethylene-coated coupons of dimension $5 \times 30 \times 50 \mathrm{~mm}$ with an $8 \mathrm{~mm}$ diameter hole and surface area of $3551 \mathrm{~mm}^{2}$ each were prepared. Four test media were prepared for this investigation: One, 201 of distilled water in a rectangular base plastic container. Two, 201 of distilled water in a rectangular base plastic container in which $200 \mathrm{~g}$ of sodium chloride $(\mathrm{NaCl})$ was dissolved entirely, giving a concentration of $10 \mathrm{~g} / \mathrm{l}$ $\left(0.01 \mathrm{~g} / \mathrm{cm}^{2}\right)$.Similarly, the third medium is 201 of 
distilled water in which $300 \mathrm{~g}$ of $\mathrm{NaCl}$ was dissolved entirely, having $15 \mathrm{~g} / 1\left(0.015 \mathrm{~g} / \mathrm{cm}^{2}\right)$ concentration. The fourth medium is prepared by dissolving $400 \mathrm{~g}$ of $\mathrm{NaCl}$ in 201 of distilled water, resulting in $20 \mathrm{~g} / 1\left(0.02 \mathrm{~g} / \mathrm{cm}^{2}\right)$ concentration. The container used for each medium is a rectangular base plastic container. Seven coated coupons each were completely immersed in 10,15 , and $20 \mathrm{~g} / 1$ and zero salinity distilled water. Similarly, seven uncoated coupons each were completely immersed in 10, 15, and $20 \mathrm{~g} / 1$ and zero salinity distilled water. The coupons in various test media were exposed to ambient temperature for a total of 49 days. One coupon from each of the media is reweighed on weekly bases, and the weight loss, corrosion rate (mm/year), and corrosion inhibition efficiency are then calculated.

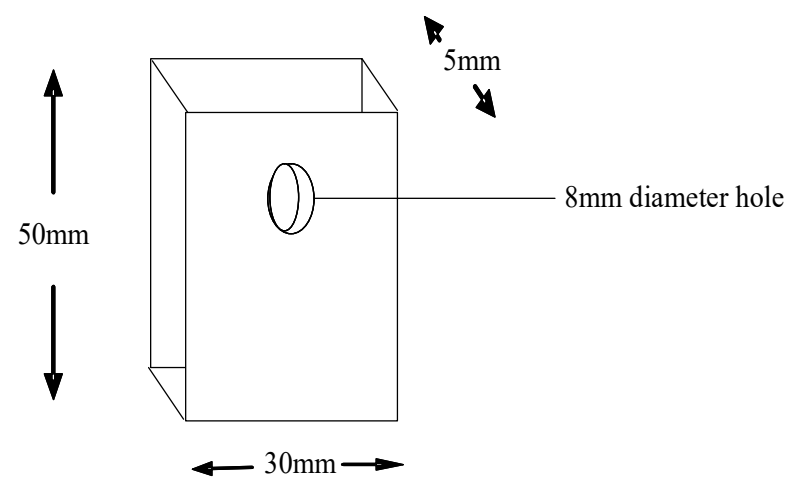

Figure 1-Geometry of coupons used
The average total surface area of the coupon, $A=3555 \mathrm{~mm}^{2} \quad\left(35.55 \mathrm{~cm}^{2}\right)$. The average result is following:

$$
x=\frac{x_{1}+x_{2}+x_{3}}{3},
$$

where $\% C E$ - percentage carbon equivalence; $Y S-$ yield strength $\left(\mathrm{N} / \mathrm{m}^{2}\right) ; \% E$ - percentage elongation.

In this work, weight loss $\Delta m(\mathrm{~g})$ is the difference between the initial weight of the coupon and its weight when reweighed, otherwise called weight loss, while $\Delta$ is weight loss per unit area of the coupon.

$$
\Delta m=m_{o}-m ; \Delta=\Delta m / A,
$$

where $m_{\mathrm{o}}-$ the initial weight of coupon; $m-$ the weight of coupon at the end of its exposure time; $A$ - the total surface area of coupon exposed to the medium.

The corrosion rate in millimeter per year $(\mathrm{mm} / \mathrm{year})$ is given as follows:

$$
C R=365.25 \cdot \Delta m /(D A T),
$$

where $C R$ - corrosion rate, $\mathrm{mm} /$ year; $D=7860 \mathrm{~kg} / \mathrm{m}^{3}$ density of alloy steel; $T$ - exposure time, days.

Percentage corrosion inhibition efficiency:

$$
\% I E=100 \cdot(C R O-C R) /(C R O),
$$

\begin{tabular}{|c|c|c|c|c|c|c|c|c|c|c|}
\hline \multirow{3}{*}{$\begin{array}{l}\text { Coupon } \\
\text { tag }\end{array}$} & \multicolumn{7}{|c|}{ Chemical composition, \% } & \multirow[t]{3}{*}{$\% C E$} & \multirow{2}{*}{\multicolumn{2}{|c|}{$\begin{array}{l}\text { Mechanical } \\
\text { properties }\end{array}$}} \\
\hline & \multirow{2}{*}{$\mathrm{C}$} & \multirow{2}{*}{$\mathrm{Mn}$} & \multirow{2}{*}{ Mo } & \multirow{2}{*}{$\mathrm{V}$} & \multirow{2}{*}{$\mathrm{Cr}$} & \multirow{2}{*}{$\mathrm{Cu}$} & \multirow{2}{*}{$\mathrm{Ni}$} & & & \\
\hline & & & & & & & & & $Y S$ & $\% E$ \\
\hline$X 1$ & 0.2250 & 0.6120 & 0.0022 & 0.0033 & 0.0048 & 0.0056 & 0.0037 & 0.3297 & 275.00 & 23.50 \\
\hline$X 2$ & 0.2249 & 0.6076 & 0.0023 & 0.0036 & 0.0053 & 0.0059 & 0.0035 & 0.3290 & 277.00 & 22.50 \\
\hline$X 3$ & 0.2251 & 0.6104 & 0.0021 & 0.0036 & 0.0052 & 0.0059 & 0.0036 & 0.3296 & 276.00 & 23.00 \\
\hline$X$ & 0.2250 & 0.6100 & 0.0022 & 0.0035 & 0.0051 & 0.0058 & 0.0036 & 0.3295 & 276.00 & 23.00 \\
\hline
\end{tabular}

where $C R^{O}$ - corrosion rate of the uncoated coupons; $C R$ - corrosion rate of coated coupon.

Table 1 - Chemical composition of the coupons used

\section{Results}

The weight loss, weight loss per unit area, corrosion rates, and corrosion inhibition efficiencies at different time intervals are presented in tabular form as shown in Tables 2-5. Also, Figures 2-4 show the variation of corrosion rates of polyethylene coated coupons with sodium chloride concentration, the variation of corrosion rates of uncoated coupons with sodium chloride concentration, and the variation of corrosion inhibition efficiencies of polyethylene coated coupons with sodium chloride concentration.

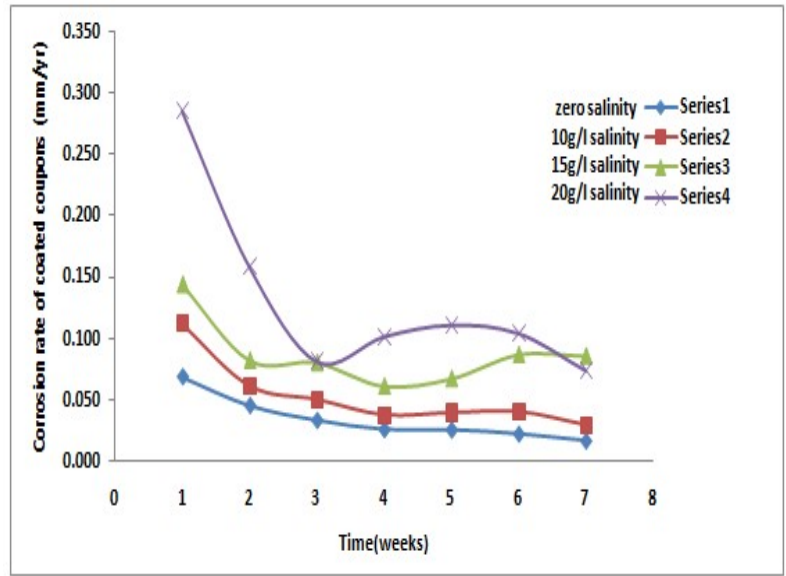

Figure 2 - Variation of corrosion rates of polyethylene coated coupons with sodium chloride concentration 


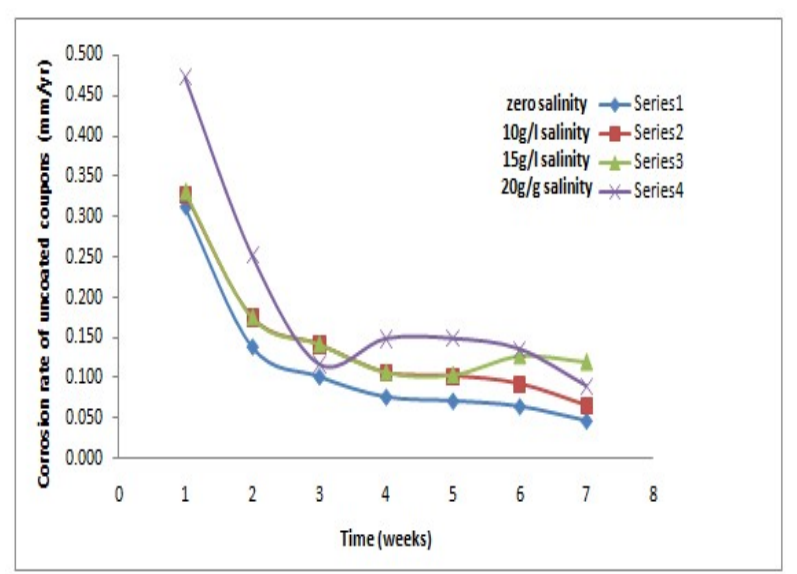

Figure 3 - The variation of corrosion rates of uncoated coupons with sodium chloride concentration

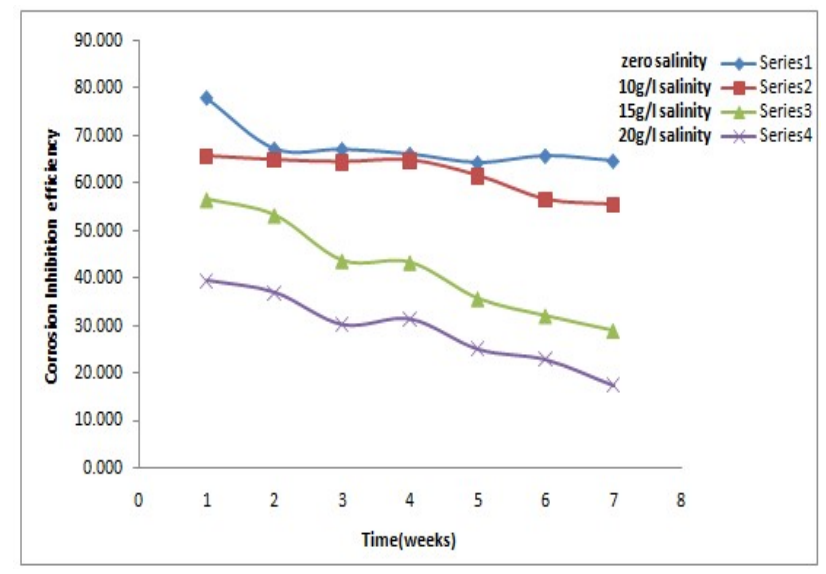

Figure 4 - The variation of corrosion inhibition efficiencies of polyethylene coated coupons with sodium chloride concentration

Table 2 - Corrosion parameters of coated coupons (zero and $10 \mathrm{~g} / \mathrm{l}$ salinity)

\begin{tabular}{|c|c|c|c|c|c|c|c|c|c|c|c|c|c|c|}
\hline \multirow{2}{*}{$\begin{array}{c}\text { Medium } \\
\text { Time(days) }\end{array}$} & \multicolumn{7}{|c|}{ Coated coupons (zero salinity) } & \multicolumn{7}{|c|}{ Coat coupons (10 g/l salinity) } \\
\hline & 7 & 14 & 21 & 28 & 35 & 42 & 49 & 7 & 14 & 21 & 28 & 35 & 42 & 49 \\
\hline $\mathrm{M}_{\mathrm{o}}(\mathrm{g})$ & 58.20 & 57.98 & 58.31 & 58.54 & 57.38 & 58.12 & 58.40 & 58.85 & 58.16 & 58.42 & 57.80 & 58.81 & 59.00 & 58.89 \\
\hline $\mathrm{M}(\mathrm{g})$ & 57.83 & 57.49 & 57.77 & 57.98 & 56.69 & 57.40 & 57.77 & 58.25 & 57.50 & 57.61 & 56.99 & 57.75 & 57.70 & 57.78 \\
\hline$\Delta \mathrm{M}(\mathrm{g})$ & 0.370 & 0.489 & 0.540 & 0.560 & 0.690 & 0.720 & 0.630 & 0.601 & 0.660 & 0.810 & 0.809 & 1.060 & 1.299 & 1.110 \\
\hline$\Delta\left(\mathrm{g} / \mathrm{cm}^{2}\right)$ & 0.010 & 0.014 & 0.015 & 0.016 & 0.019 & 0.020 & 0.018 & 0.017 & 0.019 & 0.023 & 0.023 & 0.030 & 0.037 & 0.031 \\
\hline $\mathrm{CR}(\mathrm{mm} / \mathrm{yr})$ & 0.069 & 0.046 & 0.034 & 0.026 & 0.026 & 0.022 & 0.017 & 0.112 & 0.062 & 0.050 & 0.038 & 0.040 & 0.040 & 0.030 \\
\hline$\% \mathrm{IE}$ & 77.84 & 67.16 & 67.07 & 66.06 & 64.25 & 65.71 & 64.65 & 65.68 & 64.89 & 64.47 & 64.83 & 61.59 & 56.67 & 55.60 \\
\hline
\end{tabular}

Table 3 - Corrosion parameters of coated coupons in $(15 \mathrm{~g} / 1$ and $10 \mathrm{~g} / 1$ salinity $)$

\begin{tabular}{ccccccccccccccc}
\hline Medium & \multicolumn{4}{c}{ Coated coupons $(15 \mathrm{~g} / 1$ salinity $)$} & \multicolumn{4}{c}{ Coated coupons $(20 \mathrm{~g} / 1 \mathrm{ls}$ sanity) } \\
\hline Time $($ days $)$ & 7 & 14 & 21 & 28 & 35 & 42 & 49 & 7 & 14 & 21 & 28 & 35 & 42 & 49 \\
\hline $\mathrm{M}_{\mathrm{o}}(\mathrm{g})$ & 58.85 & 58.89 & 58.35 & 57.39 & 58.09 & 58.98 & 60.99 & 58.53 & 58.10 & 58.30 & 58.20 & 58.98 & 58.85 & 58.97 \\
\hline $\mathrm{M}(\mathrm{g})$ & 58.08 & 58.01 & 57.06 & 56.08 & 56.29 & 56.19 & 57.78 & 57.00 & 56.40 & 56.99 & 56.02 & 56.00 & 55.49 & 56.19 \\
\hline$\Delta \mathrm{M}(\mathrm{g})$ & 0.770 & 0.881 & 1.290 & 1.310 & 1.800 & 2.790 & 3.210 & 1.530 & 1.700 & 1.310 & 2.180 & 2.980 & 3.360 & 2.780 \\
\hline$\Delta\left(\mathrm{g} / \mathrm{cm}^{2}\right)$ & 0.022 & 0.025 & 0.036 & 0.037 & 0.051 & 0.078 & 0.090 & 0.043 & 0.048 & 0.037 & 0.061 & 0.084 & 0.095 & 0.078 \\
\hline $\mathrm{CR}(\mathrm{mm} / \mathrm{yr})$ & 0.144 & 0.082 & 0.080 & 0.061 & 0.067 & 0.087 & 0.086 & 0.286 & 0.159 & 0.082 & 0.102 & 0.111 & 0.105 & 0.074 \\
\hline$\% \mathrm{IE}$ & 56.50 & 53.16 & 43.67 & 43.29 & 35.71 & 32.12 & 29.01 & 39.53 & 37.04 & 30.28 & 31.45 & 25.13 & 22.94 & 17.51 \\
\hline
\end{tabular}

Table 4 - Corrosion parameters of uncoated coupons (zero and $10 \mathrm{~g} / \mathrm{l}$ salinity)

\begin{tabular}{ccccccccccccccc}
\hline Medium & \multicolumn{1}{c}{ Uncoated coupons (zero salinity) } & \multicolumn{1}{c}{ Uncoated coupons (10g/1 salinity) } \\
\hline Time $($ days $)$ & 7 & 14 & 21 & 28 & 35 & 42 & 49 & 7 & 14 & 21 & 28 & 35 & 42 & 49 \\
\hline $\mathrm{M}_{\mathrm{o}}(\mathrm{g})$ & 58.20 & 57.98 & 58.31 & 58.55 & 57.59 & 58.00 & 58.09 & 58.85 & 58.16 & 58.42 & 57.91 & 58.81 & 59.00 & 58.89 \\
\hline $\mathrm{M}(\mathrm{g})$ & 56.53 & 56.49 & 56.67 & 56.90 & 55.66 & 55.90 & 56.31 & 57.10 & 56.28 & 56.14 & 55.61 & 56.05 & 56.00 & 56.39 \\
\hline$\Delta \mathrm{M}(\mathrm{g})$ & 1.670 & 1.489 & 1.640 & 1.650 & 1.930 & 2.100 & 1.782 & 1.751 & 1.880 & 2.280 & 2.300 & 2.760 & 2.998 & 2.500 \\
\hline$\Delta\left(\mathrm{g} / \mathrm{cm}^{2}\right)$ & 0.047 & 0.042 & 0.046 & 0.046 & 0.054 & 0.059 & 0.050 & 0.049 & 0.053 & 0.064 & 0.065 & 0.078 & 0.084 & 0.070 \\
\hline $\mathrm{CR}(\mathrm{mm} / \mathrm{yr})$ & 0.312 & 0.139 & 0.102 & 0.077 & 0.072 & 0.065 & 0.048 & 0.327 & 0.176 & 0.142 & 0.107 & 0.103 & 0.093 & 0.067 \\
\hline$\% \mathrm{IE}$ & 0.00 & 0.00 & 0.00 & 0.00 & 0.00 & 0.00 & 0.00 & 0.00 & 0.00 & 0.00 & 0.00 & 0.00 & 0.00 & 0.00 \\
\hline
\end{tabular}

Table 5 - Corrosion parameters of uncoated coupons ( $15 \mathrm{~g} / 1$ and $20 \mathrm{~g} / 1$ salinity)

\begin{tabular}{ccccccccccccccc}
\hline Medium & \multicolumn{1}{c}{ Uncoated coupons $(15 \mathrm{~g} / 1$ salinity) } & \multicolumn{4}{c}{ Uncoated coupons $(20 \mathrm{~g} / 1 \mathrm{salinity})$} \\
\hline Time $($ days $)$ & 7 & 14 & 21 & 28 & 35 & 42 & 49 & 7 & 14 & 21 & 28 & 35 & 42 & 49 \\
\hline $\mathrm{M}_{\mathrm{o}}(\mathrm{g})$ & 58.85 & 58.89 & 58.35 & 57.39 & 58.09 & 58.18 & 58.59 & 58.53 & 58.10 & 58.40 & 58.20 & 58.98 & 58.85 & 58.47 \\
\hline $\mathrm{M}(\mathrm{g})$ & 57.08 & 57.01 & 56.06 & 55.08 & 55.29 & 54.07 & 54.07 & 56.00 & 55.40 & 56.52 & 55.02 & 55.00 & 54.49 & 55.10 \\
\hline$\Delta \mathrm{M}(\mathrm{g})$ & 1.770 & 1.881 & 2.290 & 2.310 & 2.800 & 4.110 & 4.522 & 2.530 & 2.700 & 1.879 & 3.180 & 3.980 & 4.360 & 3.370 \\
\hline$\Delta\left(\mathrm{g} / \mathrm{cm}^{2}\right)$ & 0.050 & 0.053 & 0.064 & 0.065 & 0.079 & 0.116 & 0.127 & 0.071 & 0.076 & 0.053 & 0.089 & 0.112 & 0.123 & 0.095 \\
\hline $\mathrm{CR}(\mathrm{mm} / \mathrm{yr})$ & 0.331 & 0.176 & 0.143 & 0.108 & 0.105 & 0.128 & 0.121 & 0.473 & 0.252 & 0.117 & 0.149 & 0.149 & 0.136 & 0.090 \\
\hline$\% \mathrm{IE}$ & 0.00 & 0.00 & 0.00 & 0.00 & 0.00 & 0.00 & 0.00 & 0.00 & 0.00 & 0.00 & 0.00 & 0.00 & 0.00 & 0.00 \\
\hline
\end{tabular}




\section{Discussion}

Comparing Figures 2 and 3, the corrosion rates of the coated coupons are lower than those of the uncoated. It is also seen that the corrosion rates fall over time and fall more rapidly within the first week of exposure to the medium. It is also significant that the corrosion rates of coupons in distilled water of zero salinity are quite low compared with those exposed to a saline environment. However, looking at Figure 2, it is seen that the corrosion rates of the coupons at low salinity say zero, and $10 \mathrm{~g} / \mathrm{l}$ are very close. A decrease in corrosion rates with time may be due to the presence of corrosion products on the surface of the metal, which tends to inhibit the further attack of the metal by the reactive components of the medium. On the other hand, corrosion inhibition efficiencies of the coated coupons are quite high at low salinity but decrease with an increase in salinity. This indicates that an increase in sodium chloride concentration decreases the efficiency of polyethylene in protecting alloy steel against corrosion in a saline environment. This may be as a result of pores in the polyethylene resulting from uniform solidification or entrapped impurities which permit the penetration of sodium chloride solution from the medium to the metal. This also tends to weaken the bonds of the polyethylene molecules over time.

\section{Conclusions}

From the results obtained in this research, the authors conclude that corrosion protection of alloy steel with polyethylene coating may be recommended in a freshwater environment but not in saltwater since sodium chloride reduces the effectiveness of the coating. However, the authors conclude that polyethylene coating may be used to protect the alloy steel in a saline environment when the salinity is very low. Considering the decrease in inhibition efficiency over time, authors conclude that the use of polyethylene protecting alloy steel in long term maintenance projects is not recommended.

The authors recommend further research in which the durability of the coating in salt solution of different concentration may be determined with a high level of precision.

\section{References}

1. Umoru, L. E., Afonja, A. A., Ademodi, B. (2008).Corrosion study of AISI304, AISI321 and AISI430. Stainless steel in a tar digester. J. Miner. Mater. Charact. Eng., Vol. 7(4), pp. 291-299.

2. Parker, M. E., Peattie, E. G. (1988). Pipe line corrosion and cathodic protection: A Practical Manual for Corrosion Engineering, Technicians and Field Personnel. Guff Professional Publishing, Houston, USA.

3. Haryono, G. (2010). Seminar Proceedings, National Technique "Kejuangan”, ISSN 1693-4393, pp. D09-1-D09-6.

4. Wiston R. (2000). Uhlig's Corrosion Handbook. Prentice-Hall International Inc.

5. Marcus, P., Mansfield, F. B. (2006). Analytical Methods in Corrosion Science and Engineering. CRC Press, Boca Raton.

6. Gusti, D. R. (2013). Proceedings Semirata FMIPA, University of Lampung.

7. Ovri, J. E. O., Iyasara, A. C. (2013). Corrosion inhibition of stainless steel (314L) using molasses. The International Journal of Engineering and Science, Vol. 2(1), pp. 346-352.

8. Aisha H. Al-Moubaraki (2014). Corrosion protection of mild steel in acid solution using red cabbage dye. Chemical Engineering Communication, Vol. 202(8), pp. 1069-1080, doi: 10.1080/00986445.2014.907565.Motta, R. N., Oliveia, M., Megalhaes, P. S. F., Dias, A. M., Aragao, L. P., Forti, A. C., Carvalho, C. B. (2003). Plasmid mediated extended spectrum beta lactamase producing strains of enterobacteriaceae isolated from diabetes foot infections in a Brazilian diabetic centre. Brazilian Journal of Infectious Diseases, Vol. 7(2), pp. 1024-1032, doi: 10.1590/s1413-86702003000200006. 